\title{
A COMPARATIVE STUDY OF CRITICALLY ILL ELDERLY PATIENTS WITH ADULT SUBGROUPS WITH INFECTION IN A RURAL ICU
}

Rohit B. G1, Pulipati Akshaya Chowdary², Y. J. Visveswara Reddy ${ }^{3}$

1 Postgraduate Student, Department of General Medicine, PES Institute of Medical Sciences and Research, Kuppam, Andhra Pradesh, India.

2Postgraduate Student, Department of General Medicine, PES Institute of Medical Sciences and Research, Kuppam, Andhra Pradesh, India.

3Professor, Department of General Medicine, PES Institute of Medical Sciences and Research, Kuppam, Andhra Pradesh, India.

\begin{abstract}
BACKGROUND
The challenge ahead for health care in coming years is to ensure better quality of life to a large group of geriatric population. Life expectancy of all elderly patients remains limited even after successful ICU treatment. About one-third of the patients seen in PESIMSR, Kuppam region, belong to the geriatric age group. Therefore, a scientific study of critically ill patients in ICU, rural setting is warranted and hence the study is undertaken.

The aim of this study is to identify potential differences between elderly patients and among adult subgroups with infection and differences with regard to pattern of infection and outcome.
\end{abstract} ABSTRACT

\section{MATERIALS AND METHODS}

Demographic, physiological, bacteriological and therapeutic data was collected on the day of admission and regularly at prefixed intervals depending on the case until hospital discharge. Standard therapy for corresponding infection was administered and the progression and outcome were documented. Patients were divided into 4 age groups and compared among each group and comparisons were carried out among each group.

\section{RESULTS}

A total of 153 adults were enrolled in this study. Of these 25 (16.33\%) were aged 75 and older, 29 (18.95\%) were 65 to 74 , $61(39.86 \%)$ were 45 to 64 and $38(24.83 \%)$ were younger than 45 . Those aged 65 and above (9.2\%) had fewer blood stream infections than those younger than 65 (21\%). No central nervous system infections in 65 years and above, than in younger patients (7\%). A microbiological diagnosis was established less frequently in patients aged $65(40.74 \%)$ and older, than in younger patients less than 65 (57.57\%). Gram negative microorganisms were more frequent in all groups. Gram positive microorganisms were isolated more frequently from age group $>65(27.27 \%)$ than in age group $<65(21 \%)$.

\section{CONCLUSION}

Critically ill elderly patients with infection represent a significant percentage of the ICU population and emphasises that elderly patients with infection in the ICU have greater ICU and hospital mortality than younger individuals with age per se an independent risk factor for mortality. Gram negative microorganisms were associated with high mortality, especially in elderly age groups.

\section{KEY WORDS}

Rural ICU, Elderly with Infection.

HOW TO CITE THIS ARTICLE: Rohit BG, Chowdary PA, Reddy YJV. A comparative study of critically ill elderly patients with adult subgroups with infection in a rural ICU. J. Evolution Med. Dent. Sci. 2018;7(39):4252-4257, DOI: 10.14260/jemds/2018/949

\section{BACKGROUND}

Population around the world is growing old at high rate with increasing life expectancy. The elderly population is increasing in terms of absolute numbers and proportion of the overall population. The challenge ahead for health care in coming years is to ensure better quality of life to a large group of geriatric population. In India, as in 2016, the life expectancy is 67 years for males and 69 years for females and projections beyond 2016 made by United Nations have

'Financial or Other Competing Interest': None.

Submission 31-07-2018, Peer Review 10-09-2018,

Acceptance 17-09-2018, Published 24-09-2018.

Corresponding Author:

Rohit B. G,

H. No. 46/89/5A,

Narendranath Reddy Colony,

Bhudawarpet, Kurnool-518002,

Andhra Pradesh, India.

E-mail: raghuthedeathknight@gmail.com

DOI: $10.14260 /$ jemds $/ 2018 / 949$ indicated that $21 \%$ of the Indian population will be $60+$ years by $2050 .{ }^{1}$

In ICUs the reported proportion of elderly adults varies from $12 \%$ to $58 \%$, and elderly adults account for almost $60 \%$ of all ICU days. ${ }^{2}$ Furthermore, elderly patients above the age of 75 years now represent the largest group of patients admitted to the ICU setting. Life expectancy of all elderly patients remains limited even after successful ICU treatment and the care of elderly patients admitted to ICU can be complicated for several reasons. ${ }^{3}$

Data on infection in elderly patients in ICU are limited and usually describe specific subpopulations or are reports from small single centre cohorts which cannot provide an accurate general view of the characteristics of infected elderly critically ill population. 4

About one-third of the patients seen in PESIMSR, Kuppam region, belong to the geriatric age group. Therefore, a scientific study of critically ill patients in ICU is warranted and hence the study is undertaken. 


\section{Objective}

To identify potential differences between elderly patients and among adult subgroups with infection and differences with regard to pattern of infection and outcome.

\section{MATERIALS AND METHODS}

The study is a clinical, prospective, observational study conducted at PESIMSR Hospital, Intensive Care Unit. A total of 153 patients admitted in ICU were included in the study sample. The study was approved by the Ethical Committee of PESIMSR, Kuppam. Demographic, physiological, bacteriological and therapeutic data was collected on the day of the admission and regularly at prefixed intervals depending upon the case until hospital discharge. Sampling was convenient and purposive. All adult patients (18 years and above) including both community-acquired and nosocomial infections were admitted in ICU. Patients were admitted to ICU for reasons other than infection one and a half year from 1-1-2015 to 30-6-2016. For each enrolled patient complete clinical history was taken, physical examination was done, and necessary investigations were done. Infection was defined according to the definition of the International Sepsis Forum and adjudicated by the attending physician. Emergency surgery was defined as the scheduled surgery within 24 hours. Trauma admissions were defined as ICU admissions directly to or occurring as a complication of a traumatic event in the 30 days preceding admission. All other admissions were considered medical. While there is no clear definition of "elderly" in the medical literature, some of the studies classified patients older than 65 years to elderly. ${ }^{5}$ It was decided to use a cut-off of 65 in the current analysis, because this was the most widely used cut-off in previous studies. The elderly group was divided into 65 to 74 , and 75 and older as patients aged above 85 were only 5 in the present study. Individuals who were younger than 65 were classified as 18 to 44 and 45 to 64 . At the clinical end point (hospital discharge or death), duration of hospital stay, need for mechanical ventilation and final outcome of the patient were recorded.
Pre-designed questionnaire and consent forms were filled up accordingly from all the enlisted patients.

\section{Statistical Analysis}

Non-parametric test analogue of One-Way ANOVA is used. This is an extension of the Wilcoxon Rank-Sum Test, used to compare population location parameters (mean, median, etc.) among two or more groups including independent samples. It is based on the ranks of the data and for non-normal data were reported as median (Interquartile Range [IQR]). Means of 2 continuous normally distributed variables were compared by independent samples. Student's ' $t$ ' test, MannWhitney $U$ test and Kruskal-Wallis test were used respectively to compare means of 2 and 3 or more groups of variables not normally distributed. Analysis of the data was done using a software SPSS system 16.0. Microsoft Word and Excel had been used to generate graphs and tables.

\section{RESULTS}

A total of 153 adults were enrolled in this study, 25 (16.33\%) were aged 75 and older, $29(18.95 \%)$ were 65 to 74,61 (39.86\%) were 45 to 64 and 38 (24.83\%) were younger than 45.

Respiratory disorders were more frequent reasons for admission in cases aged 65 and older than in those who were younger than 65 . Neurological disorders were less frequent. Reasons for ICU admission were similar in the different elderly subgroups.

Requirement of mechanical ventilation was higher in younger age groups compared to other aged groups. There was no significant difference in the mean and standard deviation of hospital length of stay in all participants.

In case of survivors the hospital length of stay was higher in $45-64,65-64$ and $>75$ age groups than in younger age group, but no significant difference among the former age groups themselves.

\begin{tabular}{|c|c|c|c|c|c|}
\hline Characteristic & $\begin{array}{c}18-44, n=38 \\
(24.83 \%)\end{array}$ & $\begin{array}{c}45-64, n=61 \\
(39.86 \%)\end{array}$ & $\begin{array}{c}65-74, n=29 \\
(18.95 \%)\end{array}$ & $\begin{array}{c}>75, \mathrm{n}=25 \\
(16.33 \%)\end{array}$ & P-value \\
\hline Age, mean + SD & $32+7.45$ & $54.88+6.09$ & $66.86+2.386$ & $80+5.18$ & \multirow{3}{*}{0.04} \\
\hline Male, n (\%) & $25(65.78 \%)$ & $29(47.54 \%)$ & $19(65.51 \%)$ & $9(36 \%)$ & \\
\hline Female & $13(34.21 \%)$ & $32(52.46 \%)$ & $10(34.48 \%)$ & $16(64 \%)$ & \\
\hline \multicolumn{5}{|c|}{ Type of Admission, $\mathbf{n}(\%)$} & \multirow{4}{*}{0.68} \\
\hline Medical & $35(92.11 \%)$ & $58(95.08 \%)$ & $29(100 \%)$ & $25(100 \%)$ & \\
\hline Surgical & $2(5.26 \%)$ & $2(3.28 \%)$ & $0(0 \%)$ & $0(0 \%)$ & \\
\hline Trauma & $1(2.63 \%)$ & $1(1.64 \%)$ & $0(0 \%)$ & $0(0 \%)$ & \\
\hline \multicolumn{5}{|c|}{ Reason for ICU Admission, n (\%) } & \multirow{9}{*}{0.02} \\
\hline Surveillance or monitoring & $7(18.42 \%)$ & $4(6.55 \%)$ & $0(0 \%)$ & $1(4 \%)$ & \\
\hline Gastrointestinal & $8(21.05 \%)$ & $10(16.39 \%)$ & $3(10.34 \%)$ & $4(16 \%)$ & \\
\hline Respiratory & $13(34.21 \%)$ & $31(50.81 \%)$ & $24(82.75 \%)$ & $19(76 \%)$ & \\
\hline Renal & $821.05 \%)$ & $14(22.95 \%)$ & $4(13.79 \%)$ & $3(12 \%)$ & \\
\hline Neurological & $7(18.42 \%)$ & $7(11.47 \%)$ & $4(13.79 \%)$ & $5(20 \%)$ & \\
\hline Cardiovascular & $0(0)$ & $8(13.11 \%)$ & $4(13.79 \%)$ & $6(24 \%)$ & \\
\hline Trauma & $1(2.63 \%)$ & $2(3.27 \%)$ & $0(0 \%)$ & $0(0 \%)$ & \\
\hline Other & $12(31.57 \%)$ & $13(21.31 \%)$ & $2(6.89 \%)$ & $3(12 \%)$ & \\
\hline \multicolumn{5}{|c|}{ All Participants } & \\
\hline & Median (IQR) & Median (IQR) & Median (IQR) & Median (IQR) & Median (IQR) \\
\hline Hospital LOS & $12(3)$ & $11(3)$ & $10(6)$ & $13(9)$ & 0.68 \\
\hline \multicolumn{5}{|c|}{ Survivors } & \\
\hline Length of Stay & $11(7)$ & $14(8)$ & $14(5)$ & $13(2)$ & 0.67 \\
\hline
\end{tabular}




\begin{tabular}{|c|c|c|c|c|c|}
\hline \multicolumn{5}{|c|}{ Outcome n (\%) } & $15(60 \%)$ \\
\hline Discharged & $23(60.53 \%)$ & $40(65.57 \%)$ & $12(41.38 \%)$ & $10(40 \%)$ & 0.31 \\
\hline Expired & $15(39.47 \%)$ & $21(34.43 \%)$ & $17(58.62 \%)$ & $14(56 \%)$ & \\
\hline Mechanical ventilation n (\%) & $29(76.32 \%)$ & $33(54.1 \%)$ & $13(44.83 \%)$ & according to Age \\
\hline
\end{tabular}

Bloodstream infections occurred less frequently in participants aged 65 and older than in the younger group (18-44). Central nervous system infections were absent in participants aged 65 and older than in those aged 18 to 44 and 45 to 64 . Infection site involving respiratory system was high in age groups above 45. Other components included Oral candidiasis, Cellulitis, Syphilis, Leprosy, Bed sore, Diabetic ulcers, Abscesses and Herpes infections. Positive isolates was highest in younger age groups compared to other age groups.

\begin{tabular}{|c|c|c|c|c|c|}
\hline Infection Site n (\%) & $\mathbf{1 8 - 4 4}$ & $\mathbf{4 5 - 6 4}$ & $\mathbf{6 5 - 7 4}$ & $>\mathbf{7 5}$ & P-value \\
\hline Respiratory & $17(44.73 \%)$ & $44(72.13 \%)$ & $23(79.31 \%)$ & $20(80 \%)$ & 0.004 \\
\hline Abdominal & $6(15.78 \%)$ & $7(11.47 \%)$ & $2(6.89 \%)$ & $3(12 \%)$ & 0.74 \\
\hline Blood stream & $14(36.84 \%)$ & $7(11.47 \%)$ & $1(3.44 \%)$ & $4(16 \%)$ & 0.001 \\
\hline Renal or urinary tract & $3(7.89 \%)$ & $8(13.11 \%)$ & $3(10.34 \%)$ & $4(16 \%)$ & 0.77 \\
\hline Intravascular catheter related & $1(2.63 \%)$ & $0(0 \%)$ & $0(0 \%)$ & $0(0 \%)$ & 0.38 \\
\hline Central nervous system & $4(10.52 \%)$ & $3(4.91 \%)$ & $0(0 \%)$ & $0(0 \%)$ & 0.13 \\
\hline Other & $4(10.52 \%)$ & $9(14.75 \%)$ & $3(10.34 \%)$ & $4(16 \%)$ & 0.86 \\
\hline Positive isolates & $25(65.79 \%)$ & $32(52.46 \%)$ & $12(41.38 \%)$ & $10(40 \%)$ & 0.13 \\
\hline
\end{tabular}

Table 2. Site of Infection of all patients in the Intensive Care Unit according to Age

In individuals in the ICU believed to have an infection, a microbiological diagnosis was established less frequently in participants aged 65 and older than in those who were younger than 65. Positive isolates were highest in younger age groups compared to other age groups.

\section{Total Positive Isolates: 79 (n)}

The sum of the percentages may be $>100$ for reason for ICU admission, because of the involvement of more than one system.

The sum of the percentages may be $>100$, because of the presence of more than one site of infection in some participants.

Gram-negative microorganisms were more frequent in all groups. Gram-positive microorganisms were higher in 45 - 64 and 65 - 74 age groups compared to older and younger age groups. Viral isolates were highest in younger age groups
(18 - 44) than other age groups. Other bacteria included tuberculosis and treponema pallidum.

Isolation of other gram-positive bacteria were higher among 45 - 64 age group. These bacteria could not be differentiated into corresponding species. Isolation of Klebsiella species was highest among $45-64$ age groups compared to other age groups. Isolation of pseudomonas was higher in younger age groups (18 - 44) compared to other age groups. Non-fermenting gram negative bacilli was highest in 45 - 64 age group than other age groups. Overall, commonest isolation among all age groups was Klebsiella species and non-fermenting gram negative bacilli (a total of 17 times) followed by Pseudomonas aeruginosa (a total of 11 times) Candida species were isolated 7 times in all age groups. Dengue antigen test was positive for 16 patients in all age groups, commonest being the younger age groups (18 - 44).

\begin{tabular}{|c|c|c|c|c|c|}
\hline Microorganism, n (\%) & $\begin{array}{c}18-44, n=25 \\
(31.64 \%)\end{array}$ & $\begin{array}{c}45-64, n=32 \\
(40.50 \%)\end{array}$ & $\begin{array}{c}65-74, n=12 \\
(15.18 \%)\end{array}$ & $\begin{array}{c}>75, n=10 \\
(12.65 \%)\end{array}$ & P-value \\
\hline Gram-positive & $3(12 \%)$ & $9(28.12 \%)$ & $4(33.33 \%)$ & $2(20 \%)$ & \multirow{6}{*}{0.29} \\
\hline Gram-negative & $11(44 \%)$ & $15(46.87 \%)$ & $5(41.66 \%)$ & $5(50 \%)$ & \\
\hline Other bacteria & $0(0 \%)$ & $0(0 \%)$ & $1(8.33 \%)$ & $0(0 \%)$ & \\
\hline Fungi & $1(25 \%)$ & $1(3.125 \%)$ & $1(8.33 \%)$ & $2(20 \%)$ & \\
\hline Viruses & $7(28 \%)$ & $5(15.62 \%)$ & $0(0 \%)$ & $1(10 \%)$ & \\
\hline Parasites & $3(12 \%)$ & $2(6.25 \%)$ & $1(8.33 \%)$ & $0(0 \%)$ & \\
\hline \multicolumn{5}{|l|}{ Species } & \multirow{12}{*}{0.63} \\
\hline Staphylococcus aureus & $1(4 \%)$ & $2(6.25 \%)$ & $0(0 \%)$ & $1(10 \%)$ & \\
\hline MRSA & $0(0 \%)$ & $1(3.12 \%)$ & $0(0 \%)$ & $0(0 \%)$ & \\
\hline CONS & $1(4 \%)$ & $1(3.12 \%)$ & $3(25 \%)$ & $1(10 \%)$ & \\
\hline Streptococcus pneumoniae & $0(0 \%)$ & $1(3.12 \%)$ & $1(8.33 \%)$ & $0(0 \%)$ & \\
\hline Other gram-positive & $2(8 \%)$ & $7(21.87 \%)$ & $1(8.33 \%)$ & $0(0 \%)$ & \\
\hline Escherichia coli & $1(4 \%)$ & $2(6.25 \%)$ & $1(8.33 \%)$ & $2(20 \%)$ & \\
\hline Enterococcus & $1(4 \%)$ & $1(3.12 \%)$ & $1(8.33 \%)$ & $0(0 \%)$ & \\
\hline Klebsiella spp. & $4(16 \%)$ & $7(21.87 \%)$ & $4(33.33 \%)$ & $2(20 \%)$ & \\
\hline Pseudomonas spp. & $5(20 \%)$ & $2(6.25 \%)$ & $2(16.66 \%)$ & $2(20 \%)$ & \\
\hline Acinetobacter spp. & $2(8 \%)$ & $2(6.25 \%)$ & $1(8.33 \%)$ & $0(0 \%)$ & \\
\hline Citrobacter & $0(0 \%)$ & $1(3.12 \%)$ & $0(0 \%)$ & $0(0 \%)$ & \\
\hline
\end{tabular}




\begin{tabular}{|c|c|c|c|c|}
\hline Proteus mirabilis & $1(4 \%)$ & $0(0 \%)$ & $0(0 \%)$ & $0(0 \%)$ \\
\hline Non-fermenting Gram-negative bacilli & $4(16 \%)$ & $9(28.12 \%)$ & $1(8.33 \%)$ & $4(40 \%)$ \\
\hline Other gram-negative & $2(8 \%)$ & $2(6.25 \%)$ & $2(16.66 \%)$ & $0(0 \%)$ \\
\hline Acid-fast bacilli & $1(4 \%)$ & $0(0 \%)$ & $0(0 \%)$ & $0(0 \%)$ \\
\hline Treponema pallidum & $0(0 \%)$ & $0(0 \%)$ & $1(8.33 \%)$ & $0(0 \%)$ \\
\hline Candida spp. & $2(8 \%)$ & $1(3.12 \%)$ & $2(16.66 \%)$ & $2(20 \%)$ \\
\hline P. falciparum & $3(12 \%)$ & $2(6.25 \%)$ & $0(0 \%)$ & $0(0 \%)$ \\
\hline Plasmodium vivax & $0(0 \%)$ & $0(0 \%)$ & $1(8.33 \%)$ & $0(0 \%)$ \\
\hline Dengue virus & $8(32 \%)$ & $6(18.75 \%)$ & $0(0 \%)$ & $2(20 \%)$ \\
\hline
\end{tabular}

Table 3. Distribution of Microorganisms in individuals in the Intensive Care Unit with Documented Infection (with Positive Isolates)

The sum of percentages is $>100$, because of the isolation of more than one microorganism in some participants. Incidence of nosocomial infections was highest in younger age group (18 - 44) $26 \%$ followed by $19.67 \%$ in 45 - 64 age group and least being in age group $>75$.

\begin{tabular}{|c|c|c|c|c|c|}
\hline \multirow{2}{*}{$\begin{array}{c}\text { Nosocomial } \\
\text { Infections, n (\%) }\end{array}$} & $\begin{array}{c}\mathbf{1 8 - 4 4} \\
\mathbf{n = 3 8}\end{array}$ & $\begin{array}{c}\mathbf{4 5 - 6 4} \\
\mathbf{n}=\mathbf{6 1}\end{array}$ & $\begin{array}{c}\mathbf{6 5 - 7 4} \\
\mathbf{n = 2 9}\end{array}$ & $\begin{array}{c}\mathbf{7 5 5} \\
\mathbf{n = 2 5}\end{array}$ & $\begin{array}{c}\text { P- } \\
\text { value }\end{array}$ \\
\cline { 2 - 6 } & 10 & 12 & 5 & 3 & \\
& $(26 \%)$ & $(19.67 \%)$ & $(17.24 \%)$ & $(12 \%)$ & 0.55 \\
\hline
\end{tabular}

The mortality was highest among 65-74 age group, which was $58.62 \%$ followed by 75 and above age group which was $40 \%$. The mortality was lower in younger age groups, $18-44$ (39.43\%) and in 45 - 64 it was $34.43 \%$.

\section{DISCUSSION}

The number of older persons in developing countries has increased rapidly in recent years. While geriatric health services have undergone great advancements in developed countries over the past few decades. These services are lagging behind in India. This has resulted in a paucity of epidemiological data on ageing and associated burden of disease.

EPIC II study was performed on May 8, 2007, and involving 1246 ICUs from 75 countries worldwide. It was a one-day, prospective, multicentre and International pointprevalence study of ICU infections. This study mainly aims to determine the effect of age on patterns of infection and on outcomes in individuals with infection based on which the current study has been undertaken in a rural health care centre.

\section{Age Group}

The majority of the patients were in the $45-64$ years' age group $(61,39.86 \%)$ with a mean age of $54.88 \%$ years.

The analysis of the database compared to older and adult subgroups in the ICU with infection in terms of severity and patterns of infection. By including a follow-up period and assessing outcome at hospital discharge, it was also possible to compare survival rates between groups. This study highlights the large number of elderly adults with infections in ICU and also that individuals aged 75 and older represent an important proportion of the ICU population with infection (16.33\%). Out of 153 patients admitted in ICU, 5 of them were aged 85 and above.

\begin{tabular}{|c|c|c|}
\hline Study & $\begin{array}{c}\text { Age Group } \\
\text { (65 and Above) }\end{array}$ & $\begin{array}{c}\text { Mortality in Patients Aged } \\
\mathbf{6 5} \text { and Above }\end{array}$ \\
\hline $\begin{array}{c}\text { EPIC II } \\
\text { Study }\end{array}$ & $51.4 \%$ & $30.22 \%$ \\
\hline $\begin{array}{c}\text { Present } \\
\text { Study }\end{array}$ & $35.29 \%$ & $42.85 \%$ \\
\hline $\begin{array}{c}\text { Table 5. Comparison of patients of Age Group } \mathbf{6 5} \text { and } \\
\text { Above in the Study Group with Other Studies and Mortality } \\
\text { in that Group }\end{array}$ \\
\hline
\end{tabular}

EPIC II included $24.2 \%$ of $65-74,19.8 \%$ of $75-84$ and $4.7 \%$ of $85+$ age group in its study. The proportion of population aged between 65 and above $(35.29 \%)$ were lower to those reported in EPIC II study.

The results of this study showed that mortality was higher to those from previous reports showing that advanced age is associated with greater mortality in hospitalised individuals with infection. EPIC II study reported $30.22 \%$ of ICU mortality in 65 and above age group.

The present study showed $50 \%$ of mortality in 65 and above age group and $42.85 \%$ among all age groups.

Mechanical ventilation has been challenging for the management of elderly patients, as they develop dependence and hence are prone for ventilated associated pneumonias. Current study revealed mortality of $42.59 \%$ in $65+$ age groups of all age groups, who had to be mechanically ventilated.

\section{Nosocomial Infections}

The increased morbidity and mortality associated with nosocomial infections in the ICU is a matter of serious concern today.

\begin{tabular}{|c|c|c|c|}
\hline Current Study & $<\mathbf{6 4} \mathbf{n = 9 9}$ & $\mathbf{> 6 5} \mathbf{n = 5 4}$ & P-value \\
\hline $\begin{array}{c}\text { Nosocomial Infections } \\
\mathrm{n}(\%)\end{array}$ & $\begin{array}{c}22 \\
(22.22 \%)\end{array}$ & $8(15 \%)$ & 0.27 \\
\hline Table 6. Incidence of Nosocomial Infections in <64 and >65 \\
Age Groups \\
\hline
\end{tabular}

The current study revealed that incidence of nosocomial infections were higher in non-elderly age groups. No definitive conclusions could be drawn, because the sample size is small. Current study revealed that out of 153 patients, 41 had community acquired pneumonia and mortality increased with age.

\begin{tabular}{|c|c|c|c|c|c|}
\hline Age & $<\mathbf{6 0}$ & $\mathbf{6 0 - 6 9}$ & $\mathbf{7 0 - 7 9}$ & $>\mathbf{8 0}$ & P-value \\
\hline Mortality & $29 \%$ & $58 \%$ & $60 \%$ & $67 \%$ & 0.68 \\
\hline \multicolumn{6}{|c|}{ Table 7. Mortality and Age } \\
\hline
\end{tabular}


Current study showed highest incidence of mortality in age group of 60 and above with highest in subgroup $>80$.

\section{Age and Hospital Stay}

In case of survivors, hospital length of stay was higher in 45$64,65-64,>75$ age groups with highest in $>75$ group than in younger age group, but no significant difference among the former age groups themselves.

When the results were compared to EPIC II study, the median with interquartile range hospital length of stay in $>75$ age group was quite low compared to other groups, but when analysing only survivors the differences lost significance.

\begin{tabular}{|c|c|c|c|c|}
\hline \multirow{2}{*}{ Age } & \multicolumn{2}{|c|}{ Hospital LOS (Total) } & \multicolumn{2}{c|}{$\begin{array}{c}\text { Hospital LOS } \\
\text { (Survivors) }\end{array}$} \\
\cline { 2 - 5 } & $\begin{array}{c}\text { EPIC II } \\
\text { (Median) }\end{array}$ & $\begin{array}{c}\text { Current } \\
\text { (Mean) }\end{array}$ & $\begin{array}{c}\text { EPIC II } \\
\text { (Median) }\end{array}$ & $\begin{array}{c}\text { Current } \\
\text { (Mean) }\end{array}$ \\
\hline $18-44$ & 29 & 12 & 33 & 11 \\
\hline $45-64$ & 30 & 12 & 33 & 14 \\
\hline $65-74$ & 32 & 10 & 38 & 15 \\
\hline$>75$ & 27 & 13 & 34 & 13 \\
\hline
\end{tabular}

Table 8. Comparison between Age Groups and their Hospital Length of Stay in EPIC II and Current Study

\section{Age and Pathogen}

Out of 153 patients in ICU, 79 positive isolates could be identified in all age groups with highest incidence in 18 - 44 age group. In EPIC II study, pathogen was less likely to be isolated in individuals aged 85 and older and next least followed by 75 - 84 age group with infection in ICU. However, in both studies, the most common type of microorganism isolated in elderly age group was gram negative microorganisms. The possible reason is due to elderly adults residing in nursing homes or long-term care facilities or receiving home care have high rates of colonisation with potentially resistant gram-negative microorganisms.

Non-fermenting gram negative bacilli were isolated in 17 patients, of whom 10 died. These species could not be differentiated in the lab, while doing culture studies. The common non-fermenting gram negative bacilli included Pseudomonas aeruginosa, Burkholderia cepacia, Stenotrophomonas maltophilia and Acinetobacter species. NFGNB was most commonly isolated among all microorganisms and was found to be associated with high mortality rate in ICU.

Klebsiella pneumonia was isolated in 15 patients, of whom 6 died.

Pseudomonas aeruginosa was isolated in 11 patients, of whom 6 died and it was found to be associated more in 18-44 age groups.

Enterococcus was isolated in 3 patients, of whom 2 survived.

MRSA was isolated in one patient through blood culture and later on developed ventilator associated pneumonia and died.

When the current study was compared to EPIC II study, EPIC II study which was done in 75 countries and 1275 ICUs reported P. aeruginosa as the most commonly isolated organism followed by Staphylococcus aureus and candida.

Both studies emphasise that these gram-negative bacilli are associated with high mortality, especially in elderly age groups. Bloodstream infections were less frequent in participants aged $65-74$ followed by $45-64$ and 75 and older than in the other participants. When the current study was compared to EPIC II study, blood stream infections were least prevalent in $>75$ age group. However, both studies reveal that blood stream infections were most commonly associated with high mortality in elderly age group.

\begin{tabular}{|c|c|c|c|c|}
\hline Age & $\mathbf{1 8 - 4 4}$ & $\mathbf{4 5 - 6 4}$ & $\mathbf{6 5 - 7 4}$ & $\mathbf{> 7 5}$ \\
\hline EPIC II study & $16 \%$ & $17 \%$ & $16 \%$ & $12 \%$ \\
\hline Current study & $37 \%$ & $12 \%$ & $3 \%$ & $16 \%$ \\
\hline
\end{tabular}

Table 9. Blood Stream Infections in Different Age Groups

It is important to note that these studies were done in western countries and very little amount of data is available in Indian studies. The present study gives various patterns of infection and their effect on each group and most importantly this study was done in a resource crunch rural area where availability of facilities are limited. Another strength is that the comparison between elderly and younger adults reflects the whole population of individuals with infection in the ICU and not just specific subgroups as was the case in several previous studies that examined individuals with specific infections (e.g. nosocomial bacteraemia or severe community-acquired pneumonia). Finally, not only elderly and younger age groups, but also subgroups of elderly adults were compared, focusing on those aged 75 and older, which although is an increasingly important group of individuals with infection in the ICU has been poorly studied.

A limitation of the current study is that the sample was small and individuals with medical conditions who required shorter ICU stays or conditions with higher mortality might have been be under-represented.

\section{CONCLUSION}

- This study showed that critically ill elderly adults with infection represent a significant percentage of the ICU population and emphasises that elderly adults with infection in the ICU have greater ICU and hospital mortality than younger individuals with age per se an independent risk factor for mortality.

- This study has revealed that several important differences exist between elderly and younger individuals as well as between elderly subgroups.

- Elderly age groups had highest mortality incidence compared to other age groups.

- Only a few elderly patients (33\%) walked out of ICU after mechanical ventilation suggesting that it is difficult to wean them off and the reverse holds good for younger age groups.

- Even though, nosocomial infections (15\%) were less compared to younger groups in the present study, elderly patients who developed nosocomial infections had a higher risk of mortality (62.5\%).

- Elderly patients are susceptible to develop gram negative infections most often and drug resistance is encountered posing great challenge to the health care team. The most common type of microorganisms isolated in elderly was gram negative microorganisms (45\%).

- Gram negative microorganisms were associated with high mortality, especially in elderly age groups (80\%). 
- $\quad$ Even though blood stream infections were less frequent in elderly age group, blood stream infections were most commonly associated with high mortality in elderly age group (60\%).

\section{REFERENCES}

[1] WHO. Life expectancy in India 2016.

[2] Dimopoulos G, Koulenti D, Blot S, et al. Critically ill elderly adults with infection: analysis of the extended prevalence of infection in intensive care study. J Am Geriatr Soc 2013;61(12):2065-71.
[3] Reyes JCL, Alonso JV, Fonseca J, et al. Characteristics and mortality of elderly patients admitted to the Intensive Care Unit of a district hospital. Indian J Crit Care Med 2016;20(7):391-7.

[4] Sligl WI, Eurich DT, Marrie TJ et al. Age still matters: prognosticating short- and long-term mortality for critically ill patients with pneumonia. Crit Care Med 2010;38(11):2126-32.

[5] Bo M, Massaia M, Raspo S, et al. Predictive factors of in-hospital mortality in older patients admitted to a medical intensive care unit. J Am Geriatric Soc 2003;51(4):529-33. 